\title{
The Frequency of Nail Changes and Disorders in Iraqi People above 50 Years 0ld
}

\author{
Azar H. Maluki ${ }^{1}$, Alaa S. Al-Hulli ${ }^{2 *}$ \\ ${ }^{1}$ Head of Dermatology Department, College of Medicine, University of Kufa, Kufa, Iraq \\ ${ }^{2}$ Ministry of Health, Baghdad, Iraq \\ Email: "alaa_alhulli@yahoo.com
}

Received 19 March 2015; accepted 31 July 2016; published 3 August 2016

Copyright (C) 2016 by authors and Scientific Research Publishing Inc.

This work is licensed under the Creative Commons Attribution International License (CC BY). http://creativecommons.org/licenses/by/4.0/

(c) (i) Open Access

\section{Abstract}

Background: Nail changes associated with ageing are common in the elderly and include characteristic modifications of color, contour, growth, surface, thickness and histology. No cutaneous examination is complete without a careful clinical evaluation of the nails. Objective: The aim of present work is to assess the frequency of senile nail changes and disorders in Iraqi people above 50 years old compared with control age group (20 - 30 years old). Patients and methods: This case-controlled, cross-sectional study was performed in the outpatient clinic of Dermatology and Venereology Department at the Kufa College of Medicine Teaching Hospital in Najaf Province in the period from September 2010 to April 2011. The study included 200 subjects, of which 100 patients were above 50 years old (study group), and the other 100 subjects were from 20 - 30 years old (control group). A detailed history from each subject was recorded to detect the onset, duration and progression of nail changes and/or disorders, their occupation and any environmental exposure. A careful examination of the nails was carried out to assess the type of nail changes, site and symmetry. Any patient with systemic disease, dermatological disease or with suspected drug intake was excluded from the study. Results: The present work has shown that many nail changes were more frequent among older age individuals than younger age group with significant statistical difference ( $p=0.043-0.000)$ like dull opaque appearance, rough lusterlessness, longitudinal ridging, altered thickness, ragged cuticle, altered contour, subungual hyperkeratosis and scaling nail folds. Chromonychia was not statistically significant (14\% of study group versus $16 \%$ of the control) with $p=0.692$. Longitudinal melanonychia was significantly higher in the study group $(6 \%$ versus $0 \%$ of the control) with $p=0.013$, while punctate leukonychia was significantly higher in the control group ( $16 \%$ versus $4 \%$ of study group) with $p=0.005$. Conclusion: Some changes of the nail are significantly correlated with advanced age like dull opaque nails, rough lusterlessness, longitudinal ridging. Therefore, these signs can be regarded as indicative of ageing of healthy Iraqi people.

\footnotetext{
${ }^{*}$ Corresponding author.
}

How to cite this paper: Maluki, A.H. and Al-Hulli, A.S. (2016) The Frequency of Nail Changes and Disorders in Iraqi People above 50 Years Old. Journal of Cosmetics, Dermatological Sciences and Applications, 6, 124-132. 


\section{Keywords}

\section{Nail Changes}

\section{Introduction}

\subsection{Nail Changes \& Disorders in the Elderly}

Though nail disorders can affect any age, some of the diseases have a predilection for the aged [1]. Pre-existing disorders may also be modified by progressive ageing. First and fifth digits are most commonly involved, with other digits being affected with varying frequency [2]. Nail disorders comprise approximately $10 \%$ of all dermatologic conditions, the prevalence being higher in the elderly [1] [3].

The senile changes are presumably due to impaired peripheral circulation. Frequently arteriosclerosis is the cause, though it may not be marked [2].

Trauma, faulty biomechanics, infections, concurrent dermatological or systemic diseases and their treatments are also contributory factors [1] [4].

Changes which are observed in human nails as part of ageing process include:

- Alteration in chemical composition, the calcium content of the nails increases whereas iron decreases [2].

- Alteration in histology, the nail plate keratinocytes enlarge. There is an increase in the number of "pertinax bodies". The nail bed dermis shows thickening of the blood vessels and degeneration of the elastic tissue, especially beneath the pink part of the nail [5].

- Alteration in nail growth, in the elderly, the rate of nail growth decreases progressively between 25 to 100 years of age, by approximately $0.5 \%$ per year [5].

- Alteration in color, the senile nails may appear pale, dull, opaque, with the color ranging from yellow to brown or gray [5]. Lunula may be decreased or absent altogether [6].

- Alteration in contour, the senile nails usually has an increased transverse curvature and a decreased longitudinal curvature [2]. Flattening of the nail plate (platyonychia), spooning (koilonychia), pincer nail deformity (involution) is found more frequently [5].

- Alteration in surface texture, the senile nail may have increased longitudinal striations due to altered turnover rate of the matrix cells.

- Alteration in thickness and consistency, in the elderly, the nail plate thickness may increase, decrease or may remain unchanged.

\subsection{Nail Disorders among Elderlies: [2] [5]}

Common nail disorders that may affect elderly people more frequently than younger age individuals include Brittle nails which are common in persons older than 60 years and about $20 \%$ of randomly selected population is affected in one study. Females were affected more in a ratio of 2:1 [7]. They manifest as excessive longitudinal ridges, roughness of the nail plate (trachyonychia), horizontal lamellar splitting of distal nail plate (onychoschizia or onychoschisis), and irregularity of the distal edge of the nail plate [4]. Onychodystrophies such as nail plate hypertrophy (onychauxis), onychogryphosis, onycholysis, ingrowing toe nails (onychocryptosis), onychophosis, subungual hyperkeratosis, subungual corn (onychoclavus) and subungual hematoma [4], which these disorders usually result from Bony deformities of the digits or foot-to-shoe incompatibility (ill fitting shoes), can cause faulty biomechanics leading to onychodystrophies. Other disorders like Onychomycosis, Paronychia, Subungual Exostosis, Myxoid Pseudocysts, Subungual Melanoma, also reported to occur more frequently in elderly people.

Many previous studies have been done to assess the nail changes and disorders in elderly people who have various dermatological and systemic diseases, so, in this study we tried to more precisely specify those changes related to age from other changes that were due to associated conditions and treatments with advanced age.

The aim of present work is to assess the frequency of senile nail changes and disorders in Iraqi people above 50 years old compared with control age group (20 - 30 years old), because of the scarcity of such studies in our country. 


\section{Patients and Methods}

The study included 200 subjects, of them 100 persons were above 50 years old (study group), the other 100 subjects were from 20 - 30 years old (control group). The study was performed in the outpatient clinic of Dermatology and Venereology Department at the Kufa College of Medicine Teaching Hospital in Najaf Province in the period from September 2010 to April 2011, those patients came from different sites inside and outside Najaf Province. The design of study is case control, cross-sectional study of analytic purpose.

A detailed history from each subject was recorded, using questionnaire, to detect the onset, duration and progression of nail changes and/or disorders and their occupation. Environmental exposure of any precipitating factor like trauma, sport activities or even attaining abnormal posture, abnormal habits, tight shoes, use of cosmetics, any emotional upset or stressful conditions was also assessed.

A careful clinical examination of the nails was carried out including the type of nail change, site and symmetry.

A magnifying lens of $4 \times$ power was used.

The rate of growth of the left thumb nail per day was measured by observing the distal movement of a transverse scratch made on nail plate over a fixed period of time(monthly for 6 months), using a rule and magnifying lens.

\section{Inclusion criteria:}

Subjects above 50 years old of age (study group) and subjects from 20 - 30 years old (control group), of both sexes were included in the study.

\section{Exclusion criteria:}

1) Systemic diseases: chronic hepatic disease, chronic renal disease, etc.

2) Dermatological diseases: psoriasis, lichen planus, alopecia areata, eczema, genodermatosis or other congenital nail diseases.

3) Drugs: Chemotherapy, B- blockers, PUVA, Retinoids, Others.

\section{Ethical qualification:}

A signed consent from each patient was obtained. The study is approved by the Ethical Committee in Kufa College of Medicine (Reg. No.).

\section{Results}

The study included 200 Iraqi subjects. One hundred as study group (50 males, 50 females) were above 50years (mean $\pm \mathrm{SD} 67.3 \pm 7.8$ ). While 100 subjects were taken as control group (50 males, 50 females), their ages ranged $20-30$ years (mean \pm SD $22.01 \pm 1.8$ ), Table 1 .

The most common occupations for study group were housewifes $44 \%$, agriculture $24 \%$, hard laborer $14 \%$, office work $12 \%$ and other types of work $6 \%$. Environmental exposure of any precipitating factor like trauma, sport activities or even attaining abnormal posture, abnormal habits, tight shoes, use of cosmetics, any emotional upset or stressful conditions was related to many of the changes observed, in both study and control groups.

The frequency of nail changes among the study group and control group is shown in (Table 2) and (Figure 1) The following nail changes were more frequent among study group than control group with significant statistical difference $(\mathrm{p}=0.043-0.000)$ like dull opaque, rough lusterlessness, longitudinal ridging, altered thickness, ragged cuticle, altered contour, subangual hyperkeratosis and scaling nail folds. Longitudinal ridging (onychorrhexis), showed increased frequency ( $71 \%$ of the study group versus $0 \%$ of the control) with $p=0.000$. The

Table 1. Age, sex and disease duration among the study group and control group.

\begin{tabular}{ccccc}
\hline \multirow{2}{*}{ No. } & & Study group & Control (20 - 30 years) & Total \\
\cline { 3 - 5 } & & $\mathbf{1 0 0}$ (50 male, $\mathbf{5 0}$ female) & $\mathbf{1 0 0}$ (50 male, $\mathbf{5 0}$ female) & $\mathbf{2 0 0}$ \\
\hline \multirow{2}{*}{ Age (years) } & Range & $50-93$ & $20-30$ \\
& Mean & 67.3 & 22.01 \\
& $\mathrm{SD} \pm$ & 7.8 & 1.8 \\
& Range & $1-1080$ & $1-158$ \\
Duration of disease (weeks) & Median & 430 & 78 \\
& Mean & 537 & 94 \\
& $\mathrm{SD} \pm$ & \pm 64.3 & \pm 28.7 \\
\hline
\end{tabular}


Table 2. Spectrum of nail changes in study group and control group (20 - 30 years).

\begin{tabular}{|c|c|c|c|c|c|c|c|c|c|}
\hline & \multirow{3}{*}{ Nail changes } & \multicolumn{6}{|c|}{ No. of subjects } & \multirow{3}{*}{ Chi-Square } & \multirow{3}{*}{ P-value } \\
\hline & & \multicolumn{3}{|c|}{ Study group } & \multicolumn{3}{|c|}{ Control } & & \\
\hline & & $\begin{array}{c}\text { Male } \\
\text { No. \& \% }\end{array}$ & $\begin{array}{c}\text { Female } \\
\text { No. \& \% }\end{array}$ & $\begin{array}{c}\text { Total } \\
\text { No. \& \% }\end{array}$ & $\begin{array}{c}\text { Male } \\
\text { No. \& \% }\end{array}$ & $\begin{array}{c}\text { Female } \\
\text { No. \& \% }\end{array}$ & $\begin{array}{c}\text { Total } \\
\text { No. \& \% }\end{array}$ & & \\
\hline 1 & Dull opaque & $43(86 \%)$ & $42(84 \%)$ & 85 & 0 & 0 & 0 & 144.8 & 0.000 \\
\hline 2 & Rough lusterless & $44(88 \%)$ & $40(80 \%)$ & 84 & 0 & 0 & 0 & 144.8 & 0.000 \\
\hline 3 & Longitudinal ridging & $43(86 \%)$ & $28(56 \%)$ & 71 & 0 & 0 & 0 & 107.6 & 0.000 \\
\hline 4 & Altered thickness & $14(28 \%)$ & $16(32 \%)$ & 30 & 0 & 0 & 0 & 35.2 & 0.000 \\
\hline 5 & Ragged cuticle & $18(36 \%)$ & $12(24 \%)$ & 30 & $2(4 \%)$ & 0 & 2 & 29 & 0.000 \\
\hline 6 & Altered contour & $8(16 \%)$ & $20(40 \%)$ & 28 & 0 & $2(4 \%)$ & 2 & 26.5 & 0.000 \\
\hline 7 & Subungual hyperkeratosis & $12(24 \%)$ & $9(18 \%)$ & 21 & 0 & 0 & 0 & 22.2 & 0.000 \\
\hline 8 & Scaling nail folds & $4(8 \%)$ & $8(16 \%)$ & 12 & 0 & 0 & 0 & 12.7 & 0.000 \\
\hline 9 & Onychoschizia & $4(8 \%)$ & $4(8 \%)$ & 8 & 0 & 0 & 0 & 8.3 & 0.004 \\
\hline 10 & Brittle nails & $4(8 \%)$ & $4(8 \%)$ & 8 & 0 & 0 & 0 & 8.3 & 0.004 \\
\hline 11 & Onychomycosis & 0 & $5(10 \%)$ & 5 & 0 & 0 & 0 & 6.1 & 0.013 \\
\hline 12 & Shiny nails & $4(8 \%)$ & 0 & 4 & 0 & 0 & 0 & 4 & 0.043 \\
\hline 13 & Normal nails & $2(4 \%)$ & 0 & 2 & $44(88 \%)$ & $24(48 \%)$ & 68 & 95.7 & 0.000 \\
\hline 14 & Pitting & $6(12 \%)$ & $2(4 \%)$ & 8 & 0 & $2(4 \%)$ & 2 & 3.7 & 0.052 \\
\hline 15 & Onychlysis & $4(8 \%)$ & $4(8 \%)$ & 8 & 0 & $2(4 \%)$ & 2 & 3.7 & 0.052 \\
\hline 16 & Splinter hemorrhage & $4(8 \%)$ & 0 & 4 & $2(4 \%)$ & 0 & 2 & 0.687 & 0.407 \\
\hline 17 & Beau's lines & $2(4 \%)$ & $2(4 \%)$ & 4 & 0 & $4(8 \%)$ & 4 & 0 & 1.000 \\
\hline 18 & Chromonychia & $6(12 \%)$ & $8(16 \%)$ & 14 & $8(16 \%)$ & $8(16 \%)$ & 16 & 0.157 & 0.692 \\
\hline 19 & Subungual hematoma & $4(8 \%)$ & 0 & 4 & $2(4 \%)$ & 0 & 2 & 0.687 & 0.407 \\
\hline 20 & Paronychia & 0 & $3(6 \%)$ & 3 & 0 & 0 & 0 & 2.02 & 0.155 \\
\hline 21 & Trachyonychia & 0 & $2(4 \%)$ & 2 & 0 & 0 & 0 & 2.02 & 0.155 \\
\hline \multirow[t]{3}{*}{22} & Longitudinal Splitting & $2(4 \%)$ & 0 & 2 & 0 & 0 & 0 & 2.02 & 0.155 \\
\hline & Others & & & & & & & & \\
\hline & Congenital malalignment big toenail & 0 & $1(2 \%)$ & 1 & 0 & 0 & 0 & 2.02 & 0.155 \\
\hline \multirow[t]{2}{*}{23} & Glomus tumor & $1(2 \%)$ & 0 & 1 & 0 & 0 & 0 & 2.02 & 0.155 \\
\hline & Ingrowing nail & 0 & $2(4 \%)$ & 2 & 0 & $4(8 \%)$ & 4 & 0.687 & 0.407 \\
\hline
\end{tabular}

different types and distributions of altered contour in study group are shown in Figure 2, including platyonychia, koilonychia, increased transverse curvature, pincer nail (Figures 3-10), dystrophy and downward bent distal nail plate.

The different types and distributions of altered thickness of nail plate in the study group are shown in Figure 3 , including thickening, thinning and onychogryphosis.

Other changes although were statistically not significant, some of them occurred more frequently among the study group like pitting, onycholysis, paronychia; on the contrary, ingrowing nails were reported more frequently in the control group.

Chromonychia was not statistically significant ( $14 \%$ of study group versus $16 \%$ of the control) with $\mathrm{p}=$ 0.692. Longitudinal melanonychia was significantly higher in the study group (6\% versus $0 \%$ of the control) with $p=0.013$, while punctate leukonychia was significantly higher in the control group $(16 \%$ versus $4 \%$ of study group) with $\mathrm{p}=0.005$.

In each subject the rate of growth of the left thumb nail per day was measured. The mean rate of nail growth of males and females in study group were $0.087 \mathrm{~mm} /$ day and $0.068 \mathrm{~mm} /$ day respectively, and for the control group were $0.096 \mathrm{~mm} /$ day and $0.093 \mathrm{~mm} /$ day respectively. So, the rate of nail growth was higher in control 


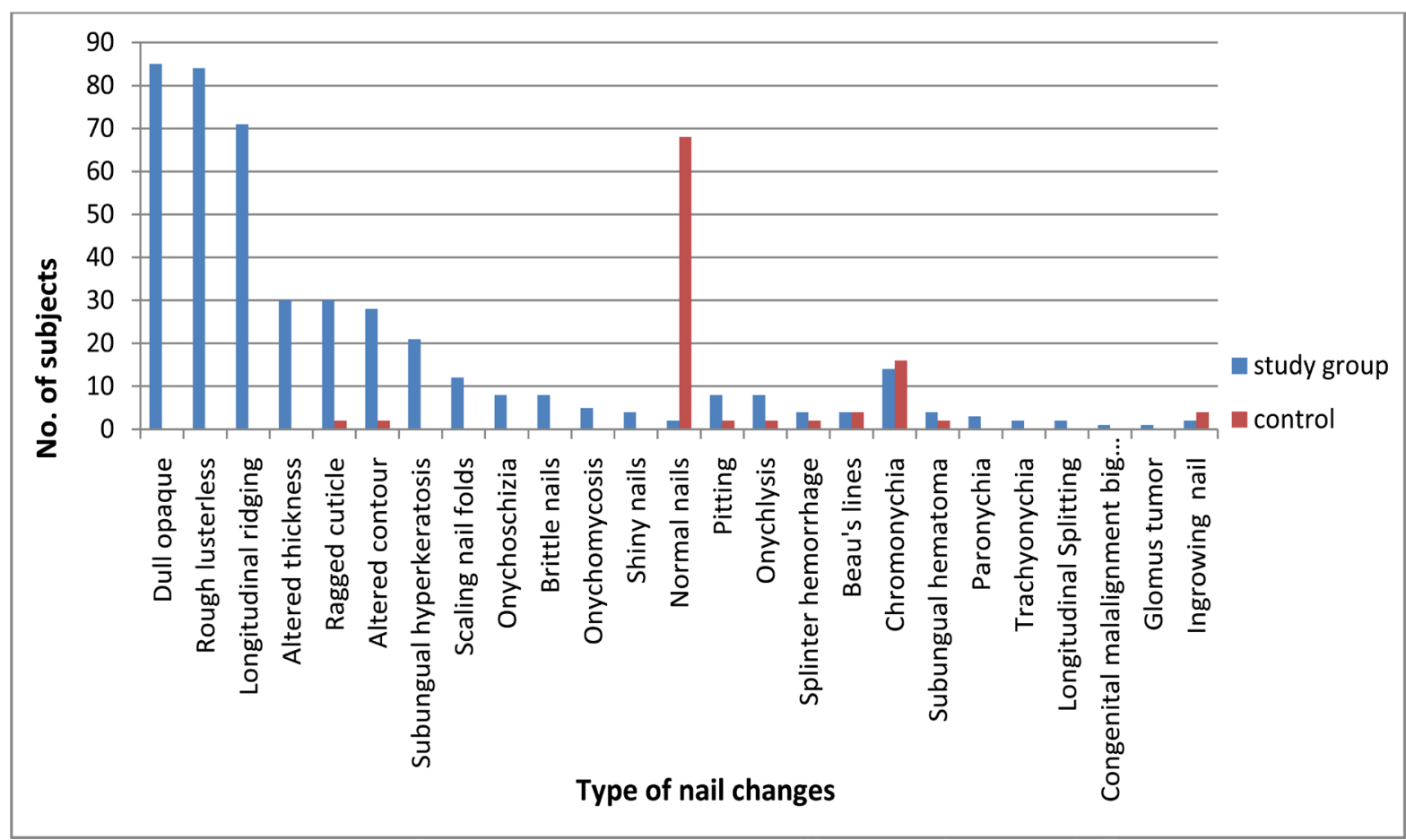

Figure 1. Spectrum of nail changes in study group and control group.

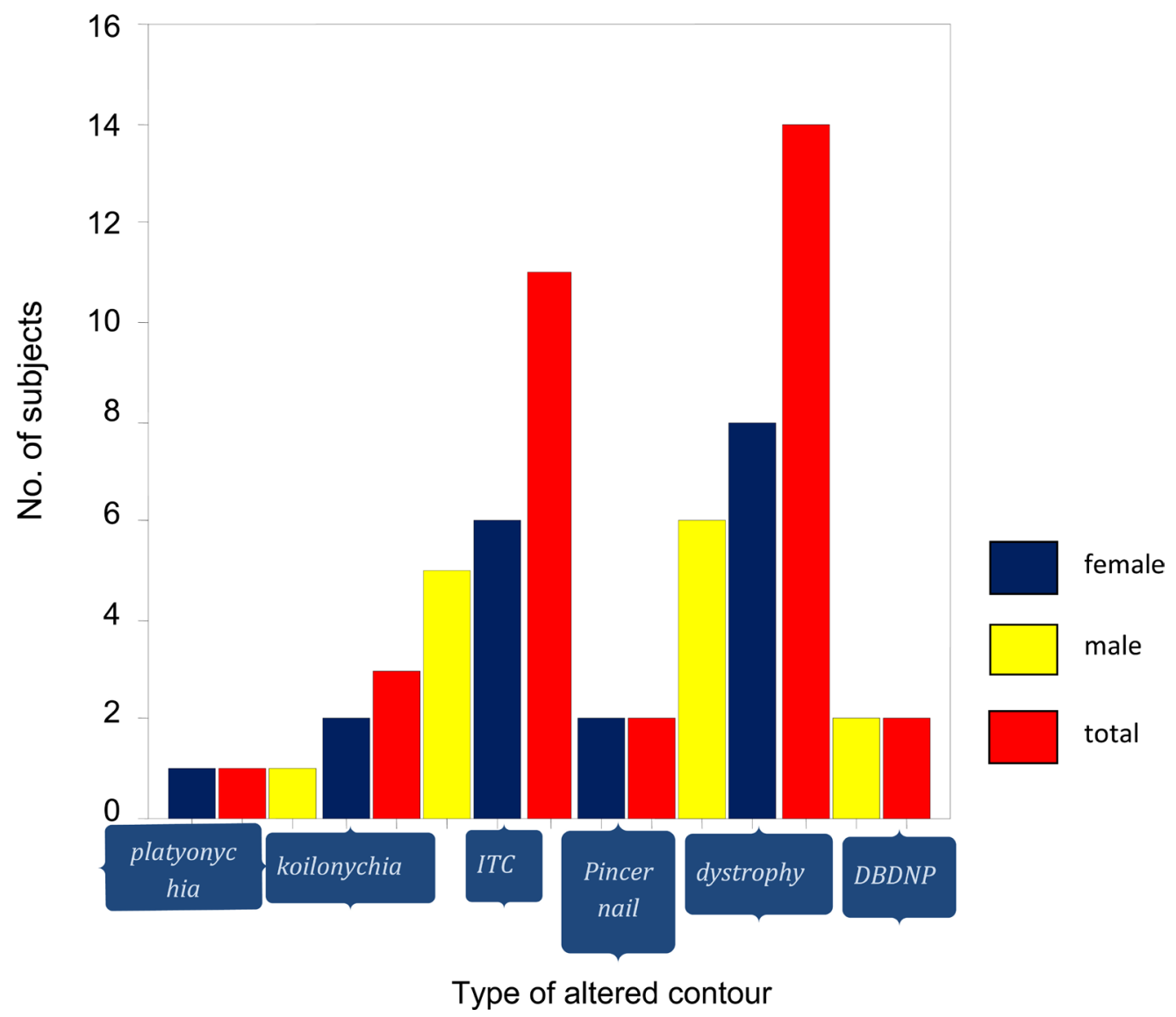

Figure 2. Type and distribution of altered contour in study group. 


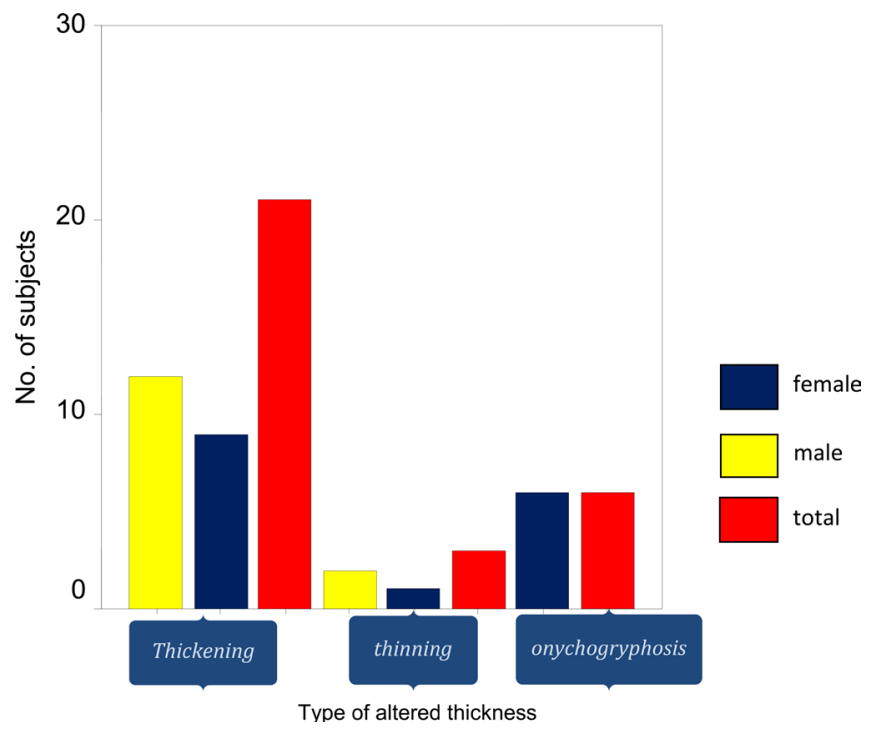

Figure 3. Type and distribution of altered thickness of nail plate in study group.

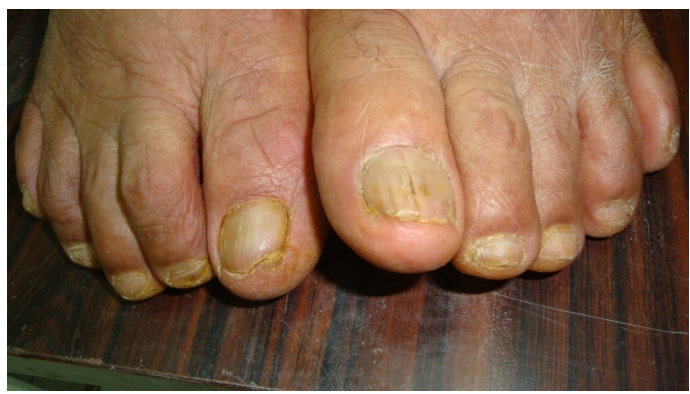

Figure 4. Longitudinal ridging and dull opaque nails, 93 years old male.

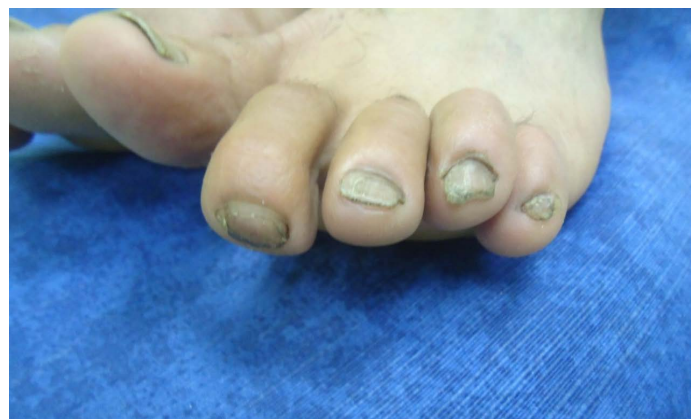

Figure 5. Dark dull opaque nails, 53 years old female.

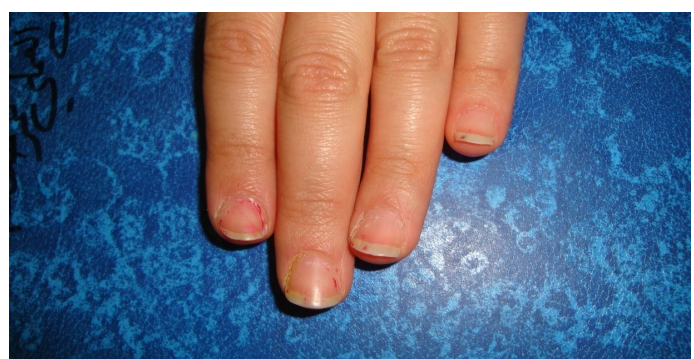

Figure 6. Onychotillomania showing ragged cuticle and bleeding. Medical student, 23 years old male. 


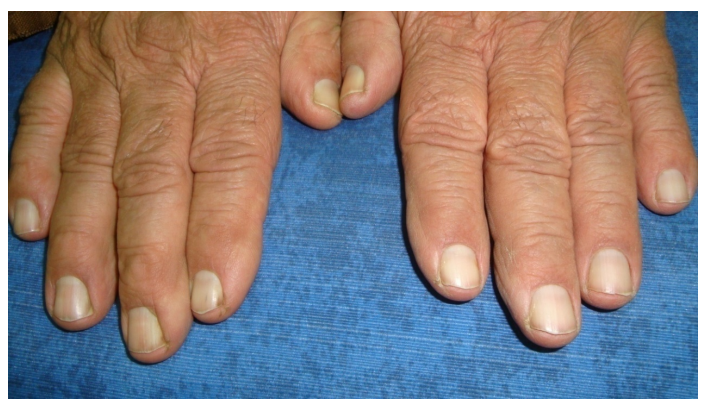

Figure 7. Pale white dull opaque nails, 70 years old man.

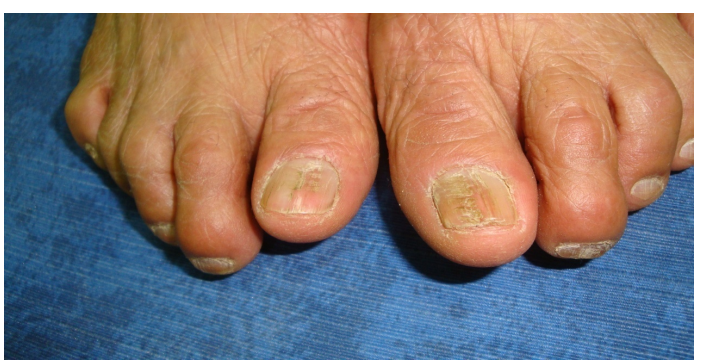

Figure 8. Median nail dystrophy, 76 years old man.

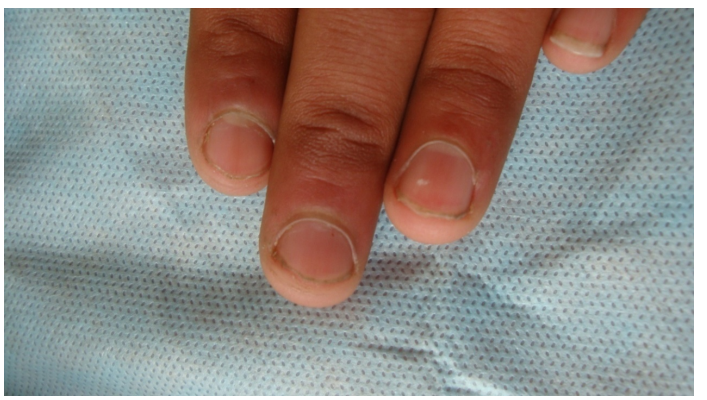

Figure 9. Punctate leukonychia, 26 years old male.

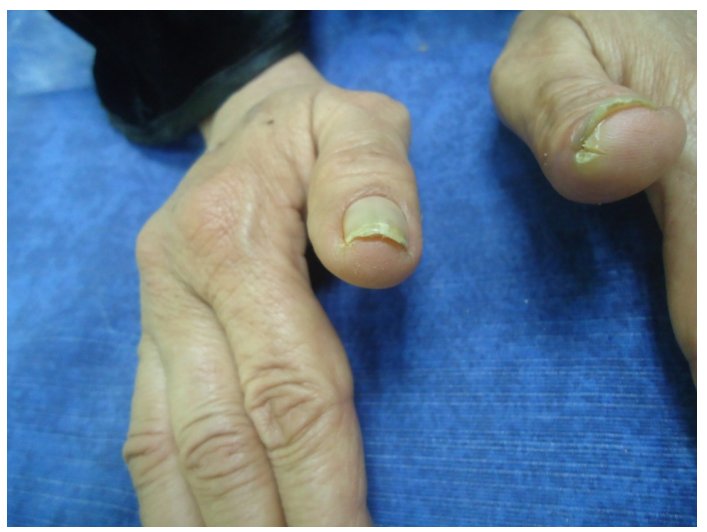

Figure 10. Pincer nails and periungual inflammation, 56 years female.

group than in study group for both sexes.

\section{Discussion}

Two hundred subjects were included in the study, one hundred as study group; their ages were above 50 years, 
the other hundred as control group aged 20 - 30 years.

In the present study, the first and fifth digits were more frequently involved, and toenail involvement was commoner than the fingernails in many of the changes, which is consistent with the literature [4].

Age related color change of the nail plate like dull opaque nails, was the commonest nail change, being observed in $(85 \%$ of the study group versus $0 \%$ of the control $)$ with $\mathrm{p}=0.000$. This is consistent with the literature [5] [8], showing that senile nail may appear pale, dull and opaque, with its color varying from white or yellow to brown to gray.

It is found that white dull opaque nails were more frequent in fingernails, while dark dull opaque nails were more frequent in toenails, as reported by another study [9].

Rough, lusterless nails were reported to occur mostly in the toes [10]. This study observed this senile nail change in $84 \%$ of the study group versus $0 \%$ of the control, with $p=0.000$, exclusively involving toenails, sparing the great toenail in majority of cases.

The present study has demonstrated that longitudinal ridging (onychorrhexis) is strongly associated with aging. The study group showed increase in frequency ( $71 \%$ versus $0 \%$ of the control) with $p=0.000$. Aging is the commonest cause of onychorrhexis or longitudinal ridging [11].

In this study it is found that both right and left thumbs were equally affected, but the left hand was generally more frequently and more significantly affected than the dominant hand especially the 4th and 5th fingers. This finding has not been reported by previous studies. The frequency was more in fingernails than in toenails.

Altered thickness of nail plate was a manifestation of aging as reported by other studies [2] [4] [5]. Similarly this study found a positive correlation between aging and this nail change (30\% of the study group versus $0 \%$ of the control) with $\mathrm{p}=0.000$. It was more common in toenails. Thickening was more prevalent in first and fifth toenails of each foot.

Altered contour of nail plate is also significantly correlated with increased age (28\% of the study group versus $2 \%$ of the control) with $\mathrm{p}=0.000$. This is also reported as an important senile nail change in literature [2] [5]. Altered contour of nail plate in the form of platyonychia in 1 case, koilonychias in 3 cases, increased transverse curvature in 11 cases, pincer nail 2 cases, dystrophy 14 cases and downward bent distal nail plate 2 cases. Toenails were more frequently involved.

The prevalence of Onychomycos is increases with age and reaches nearly $20 \%$ in patients above 60 years of age [12]. In our study, we found the prevalence of onychomycosis to be (5\% study group vs $0 \%$ control) $\mathrm{p}=0.013$ which is significant. Onychomycosis has been reported to be more common in elderly men than elderly women. In our study we found that onychomycosis exclusively affected women.

Although chromonychia is reported as a senile nail change in literature [9], however, this study did not show a significant correlation with age ( $14 \%$ of the study group versus $16 \%$ of the control) with $p=0.692$, while longitudinal melanonychia was significantly higher in the study group ( $6 \%$ versus $0 \%$ of the control) with $p=0.013$, and punctate leukonychia was significantly higher in control group (16\% versus $4 \%$ of the study group) with $p=$ 0.005 . The higher prevalence of punctate leukonychia in fingernails among younger age group is also reported earlier being possibly due to microtrauma [13].

The rate of nail growth was higher in control group than in study group for both sexes, this is consistent with previous studies. [14] [15] which showed progressive slowing of nail growth rate with advanced age.

Some Limitation of this study, may be, a larger number of subjects and a multicentre study may be required to more precisely assess the nail changes and disorders in older Iraqi people.

\section{Conclusions}

- Some changes of the nail were significantly correlated with advanced age like dull opaque nails, rough lusterlessness and longitudinal ridging. Therefore, these signs can be regarded as indicative of ageing in healthy Iraqi people.

- Other disorders of the nail like pitting, onycholysis and paronychia were not age specific and, therefore, cannot be regarded as signs of ageing.

- Some other nail changes like ingrown nails and punctate leukonychia were more frequently reported in younger age individuals and hence, they were not ageing signs.

- Finger nail growth may be considered as a sign of aging of healthy Iraqi people. 


\section{References}

[1] Drake, L.A., Dinehart, S.M., Farmer, E.R., Goltz, R.W., Graham, G.F., Hordinsky, M.K., et al. (1996) Guidelines of Care for Nail Disorders. Journal of the American Academy of Dermatology, 34, 529-533. http://dx.doi.org/10.1016/S0190-9622(96)90468-5

[2] Baran, R. and Dawber, R.P.R. (1994) The Nail in Childhood and Old Age. In: Baran, R. and Dawber, R.P.R., Eds., Diseases of the Nails and Their Management, 2nd ed, Blackwell Scientific Publications, Oxford, 81-96.

[3] Raja Babu, K.K. (2001) Nail and Its Disorders. In: Valia, R.G., Valia, A.R., Bajaj, A.K., Ganapati, R., Girdhar, B.K. and Haldar, B., Eds., IADVL Textbook and Atlas of Dermatology, 2nd ed, Bhalani Publishing House, Mumbai, $763-$ 798.

[4] Cohen, P.R. and Scher, R.K. (1992) Geriatric Nail Disorders: Diagnosis and Treatment. Journal of the American Academy of Dermatology, 26, 521-531. http://dx.doi.org/10.1016/0190-9622(92)70075-Q

[5] Cohen, P.R. and Scher, R.K. (2000) Aging. In: Hordinsky, M.K., Sawaya, M.E. and Scher, R.K., Eds., Atlas of Hair and Nails, Churchill Livingstone, Philadelphia, 213-225.

[6] Cohen, P.R. (1996) The Lunula. Journal of the American Academy of Dermatology, 34, 943-953.

[7] Scher, R.K. (1989) Brittle Nails. International Journal of Dermatology, 28, 515-516. http://dx.doi.org/10.1111/j.1365-4362.1989.tb04603.x

[8] Baran, R. (2011) The Nail in the Elderly. Clinics in Dermatology, 29, 54-60. http://dx.doi.org/10.1016/j.clindermatol.2010.07.008

[9] Singh, G., Haneef, N.S. and Uday, A. (2005) Nail Changes and Disorders among the Elderly. Indian Journal of Dermatology Venereology \& Leprology, 71, 386-392. http://dx.doi.org/10.4103/0378-6323.18941

[10] Rao, S., Banerjee, S., Ghosh, S.K., Gangopadhyay, D., Jana, S. and Mridha, K. (2010) Nail Changes and Nail Disorders in the Elderly. Indian Journal of Dermatology, 55, 301-304.

[11] Holzberg, M. (2000) Nail Signs of Systemic Disease. In: Hordinsky, M.K., Sawaya, M.E. and Scher, R.K., Eds., Atlas of Hair and Nail, Churchill Livingstone, Philadelphia, 59-70.

[12] Loo, D.S. (2004) Cutaneous Fungal Infections in the Elderly. Dermatologic Clinics, 22, 33-50. http://dx.doi.org/10.1016/S0733-8635(03)00109-8

[13] Tosti, A. and Piraccini, B.M. (2008) Biology of Nails and Nail Disorders. In: Wolf, K., Goldsmith, L.A., Katz, S.I., Gilchrest, B.A., Paller, A.S. and Leffell, D.J., Eds., Fitzpatricks Dermatology in General Medicine, 7th Edition, Mc Graw-Hil, New York, 778-794.

[14] Bean, W.B. (1974) Nail Growth; 30 Years of Observation. Archives of Internal Medicine, 134, 497-502. http://dx.doi.org/10.1001/archinte.1974.00320210107015

[15] Dawber, R.P.R. and Baran, R. (1987) Nail Growth. Cutis, 39, 99-102.

\section{Scientific Research Publishing}

\section{Submit or recommend next manuscript to SCIRP and we will provide best service for you:}

Accepting pre-submission inquiries through Email, Facebook, LinkedIn, Twitter, etc.

A wide selection of journals (inclusive of 9 subjects, more than 200 journals)

Providing 24-hour high-quality service

User-friendly online submission system

Fair and swift peer-review system

Efficient typesetting and proofreading procedure

Display of the result of downloads and visits, as well as the number of cited articles

Maximum dissemination of your research work

Submit your manuscript at: http://papersubmission.scirp.org/ 